\title{
IX \\ AS POLÍTICAS DE HABITAÇÃO NO BRASIL E OS SEUS REBATIMENTOS PARA A CLASSE TRABALHADORA*
}

Maria Caroline da Silva Souza ${ }^{1}$

\section{INTRODUÇÃO}

Este capítulo foi elaborado a partir dos estudos iniciados no Núcleo de Estudos Sobre Favelas e Espaços Populares (NEPFE/UFF) e no Trabalho de Conclusão de Curso da graduação em Serviço Social da UFF e aprofundados no mestrado, ainda em curso, do Programa de Pós-Graduação em Serviço Social da UFRJ e no curso de especialização em Cidades, Políticas Urbanas e Movimentos Sociais do IPPUR/UFRJ.

Tem como objetivo trazer incursões teóricas sobre a cidade, os diferentes projetos em disputa, analisar e contextualizar a habitação no Brasil, discutindo algumas das políticas de já implantadas e os seus rebatimentos nas condições gerais de vida da classe trabalhadora. A moradia apesar de se constituir como uma necessidade humana e até aparecer na Constituição Federal de 1988 como um dos direitos sociais, sempre foi de difícil acesso a classe trabalhadora brasileira. A fim de saciar essa necessidade, ela tem de enfrentar condições adversas no seu dia a dia, como viver em habitações improvisadas e/ou precárias, dividir o mesmo domicílio com outras famílias, se adensar com outros moradores em um mesmo cômodo ou comprometer boa parte da sua renda mensal com o pa-

\footnotetext{
*DOI - 10.29388/978-65-86678-35-2-0-f.197-218

1 Assistente Social, especialista em Cidades, Políticas Urbanas e Movimentos Sociais pelo IPPUR/UFRJ, mestranda no Programa de Pós-Graduação em Serviço Social da Universidade Federal do Rio de Janeiro e integrante do Núcleo de Estudos e Pesquisas Sobre Favelas e Espaços Populares (NEPFE).
} 
gamento de aluguel. Além da possibilidade de ser removida do seu local de moradia caso ele desperte interesse ao capital.

O capítulo está dividido em três partes, além desta introdução. Na primeira parte se discute a cidade no capitalismo. Na segunda são abordados os problemas urbanos, especialmente a questão da habitação, a partir da premissa que o problema da moradia se deve a ordem social vigente. Seguido por reflexões sobre a lógica da cidade mercadoria pelos programas de habitação Banco Nacional da Habitação (BNH), o Programa Minha Casa Minha Vida e o recém instituído Programa Casa Verde e Amarela, suas implicações para a classe trabalhadora, e as considerações finais.

\section{A CIDADE NO CAPITALISMO}

Partimos da compreensão de que cidade não surgiu no capitalismo, contudo, foi a partir da transição para o modo de produção capitalista que ela foi ressignificada e adquiriu maior centralidade em relação ao campo. Para a compreensão e análise do desenvolvimento das cidades utilizamos a lei do desenvolvimento desigual e combinado elaborada por Trotsky². "Desenvolvimento desigual e combinado" porque integra dois diferentes estágios de desenvolvimento que se amalgamam. No caso, pensando a realidade brasileira, o país se desenvolveu pela combinação entre o moderno e o arcaico. Segundo Florestan Fernandes (2008), intelectual que construiu estudos adensados sobre o tema, existe um traço colonial permanente na formação social brasileira e das demais nações latino-americanas, sendo produtos de um tipo moderno de colonialismo, pois “[...] o subdesenvolvimento não é um estado produzido e mantido a partir de dentro, mas gerado, condicionado e regulado a partir de fora, por fatores estruturais e de conjuntura do mercado mundial". (FERNANDES, 2008, p. 55). Ou seja, o atraso de algumas nações ou subdesenvolvimento das mesmas é inerente à lógica capitalista.

\footnotetext{
2 “A lei do desenvolvimento desigual e combinado é uma lei científica da mais ampla aplicação no processo histórico. Tem um caráter dual ou, melhor dizendo, é uma fusão de duas leis intimamente relacionadas. $\mathrm{O}$ seu primeiro aspecto se refere às distintas proporções no crescimento da vida social. O segundo, à correlação concreta desses fatores desigualmente desenvolvidos no processo histórico.” (NOVACK, 2008, p. 17-18).
} 
Este atraso concomitante a modernização se expressa nas esferas macro e micro, Engels (2008) aponta que em nome do crescimento e da industrialização das cidades os ingleses ${ }^{3}$ tiveram que abrir mão de uma coisa muito importante: a humanidade. $\mathrm{O}$ autor também disserta como este processo não foi exclusivo de Londres:

O que é verdadeiro para Londres também é para Manchester, Birmingham e Leeds - é verdadeiro para todas as grandes cidades. Em todas as partes, indiferença bárbara e grosseiro egoísmo de um lado e, de outro, miséria indescritível; em todas as partes, a guerra social: a casa de cada um em estado de sítio; por todos os lados, pilhagem recíproca sob a proteção da lei; e tudo isso tão despudorada e abertamente que ficamos assombrados diante das consequências das nossas condições sociais, aqui apresentadas sem véus, e permanecemos espantados com o fato de este mundo enlouquecido ainda continuar funcionando. (ENGELS, 2008, p. 68-69)

Esta cidade desigual é produzida de forma inevitável pelo modo de produção capitalista para beneficiar um pequeno grupo da sociedade, em contraposição aos interesses da maioria da população, a classe trabalhadora. As cidades, tal como ela se apresentam na modernidade, foram projetadas segundo a ideologia burguesa, conforme Lefebvre (2001, p. 107) aponta:

Forças muito poderosas tendem a destruir a cidade. Um certo urbanismo, a nossa frente, projeta para a realidade a ideologia de uma prática que visa a morte da cidade. Essas forças sociais e políticas assolam o "urbano" em formação. Pode esse embrião, muito poderoso à sua maneira, nascer nas fissuras que ainda subsistem entre as massas: o Estado, a Empresa, a Cultura (que deixa a cidade perecer, oferecendo sua imagem e suas obras ao consumo), a Ciência ou antes o cientificismo (que se põe ao serviço da realidade existente, que a legitima)? (LEFEBVRE, 2001, p. 107).

Estas forças poderosas a quais Lefebvre se refere colocam seus interesses particulares acima dos interesses da população e os propagam como interesses coletivos. O resultado disto é que "[...] a cidade passa a expressar de forma

3 O autor refere-se à Inglaterra por nesta obra estar analisando A Situação da Classe Trabalhadora na Inglaterra. Contudo, este processo não foi exclusivo do referido país. 
enfática as desigualdades das relações sociais, cuja consequência na vida dos sujeitos é a degradação de sua humanidade” (FARAGE, 2014, p. 247)

Como é próprio das contradições do capitalismo, é a degradação à qual parte da população é submetida que desencadeia as lutas sociais. Com o capitalismo, a cidade tornou-se um campo de luta das classes sociais, pois, enquanto a classe trabalhadora necessita da cidade pelo seu valor de uso - para saciar uma necessidade -, a burguesia se guia pelo seu valor de troca, uma vez que para ela a cidade é uma mercadoria (MARICATO, 2015)

Todavia, as lutas urbanas têm encontrado muitos desafios, seja pela criminalização do seu movimento, pela cooptação das lideranças, organizações populares e movimentos sociais por cargos públicos ou pela ilusão da democracia participativa, que é caracterizada por Sanchez (2001) como uma participação meramente contemplativa, já que os grupos dos de baixo não tem tido poder decisório nas políticas urbanas e elas seguem sendo orientadas pelos interesses do capital, sendo remodeladas de acordo com o seu benefício.

Nesta virada de século, o que parece explicar a aproximação de certas políticas urbanas é a orientação dos respectivos governos para a transformação das cidades em mercadorias, junto à transformação da base material das cidades para o novo padrão de acumulação, sob as pressões uniformizadoras dos atores hegemônicos para a realização do mundo atual. Como resposta a essas pressões, os projetos de cidade, os modelos de desenvolvimento construídos pelos governos locais junto a agentes privados com interesses localizados, parecem guardar, de fato, semelhanças significativas. (SANCHEZ, 2001, p. 46)

Assim, o desenvolvimento do capitalismo pressupõe uma mercantilização da cidade que tem como uma de suas consequências a disputa de diferentes projetos para ela. No próximo item mostraremos como sempre existiram estes diferentes projetos de cidade, e como na formação social brasileira o lugar da classe trabalhadora sempre foi um lugar subalternizado. 


\section{PROBLEMAS URBANOS: A QUESTÃo DA HABITAÇÃO NO BRASIL}

É no começo do século XX que os problemas urbanos são reconhecidos como tal e se tornam alvo de intervenção. As intervenções se iniciam, conforme destaca Topalov (1996), com os primeiros reformadores de moradias, primeiros urbanistas, assistentes sociais e os filantropos da época que deviam de intervir na realidade das grandes cidades industriais. A sua visão estratégica e o seu objetivo era "[...] mudar a cidade para mudar a sociedade e, particularmente, o povo" (ibid., p. 23) Estes movimentos de reforma foram imprescindíveis para o surgimento das primeiras políticas sociais e urbanas.

Tanto na Europa, quanto no Rio de Janeiro, os cortiços eram vistos como lócus da pobreza por concentrarem a tida "classe perigosa". Os cortiços se constituíam como uma ameaça à ordem social e moral da época e tornaramse motivo de preocupação para as elites. Se tornam objetos de intervenção por serem vistos como um problema para o controle social dos pobres, ameaça as condições sanitárias da cidade e um obstáculo ao projeto de remodelação urbana e embelezamento da antiga capital do país. Valladares (2000) comenta como esta intervenção nos cortiços, conhecida popularmente como o "bota-abaixo", que fez remoções das áreas centrais da cidade, tem uma relação direta com o desenvolvimento inicial das favelas, pois nessa destruição foi permitido aos seus ocupantes a retirada de madeiras que poderiam ser aproveitadas em outros lugares. Alguns moradores teriam então subido o atual morro da Providência e construído novas habitações depois do desmantelamento dos cortiços. Passada a campanha contra os cortiços, que resultaram no surgimento das primeiras favelas, a atenção se volta para esse novo local geográfico que estava se consolidando como o mais recente território da pobreza. As intervenções nas favelas variam de acordo com o período histórico, sendo frequentemente resumidas nos seguintes marcos da política urbanas:

\footnotetext{
${ }^{4}$ Bota-abaixo foi como ficou popularmente conhecida a reforma urbana e sanitária promovida pelo prefeito Pereira Passos (1902-1906) no centro da cidade do Rio de Janeiro. Esta denominação se deu pelo caráter autoritário que estas reformulações urbanas ocorreram, cortiços, comércios e outros locais de moradia das camadas populares foram demolidos neste processo de urbanização e a população que vivia e trabalhava ali teve que se deslocar para regiões mais longe do centro da cidade ou subir os morros em busca de um novo local de moradia.
} 
(a) anos 30: início do processo de favelização do Rio de Janeiro e reconhecimento da existência da favela pelo Código de obras de 1937; (b) anos 40: primeira proposta de intervenção, com a criação dos Parques Proletários; (c) anos 50 até meados dos 60: período de expansão das favelas por ausência de uma proposta governamental voltada para elas; (d) meados dos anos 60 a meados dos 70: período das remoções, coincidindo com o período do regime autoritário no país; (e) anos 80: período da urbanização via $\mathrm{BNH}$ e agências do serviço público; (f) primeira metade dos 90: período de ausência de ação governamental e retomada do crescimento das favelas; $(\mathrm{g})$ segunda metade dos anos 90: período do programa Favela-Bairro, de regularização e urbanização das favelas cariocas pela Prefeitura do Rio de Janeiro. (VALLADARES, 2000, p. 26)

Existe nas cidades uma diferenciação nos lugares que as classes sociais ocupam, pois os espaços econômicos e residenciais ${ }^{5}$ se diferenciam entre si por apresentarem as características dos indivíduos que utilizam seus serviços e neles habitam. Souza (2005) aponta que no caso brasileiro o fator principal que causa esta diferenciação é a renda, ou seja, a área residencial que um indivíduo ocupa está diretamente relacionada a fração da classe trabalhadora a que ele pertence. Esta diferenciação sob o ângulo socioeconômico afeta diretamente a qualidade de vida destas pessoas, pois a classe trabalhadora é obrigada a viver em áreas periféricas e precarizadas, com problemas referentes à educação, saúde, emprego, opções de lazer, pouca circulação de renda, transporte, geralmente com altos índices de criminalidade e alvo de operações policiais violentas.

Esta diferenciação sob o ângulo socioeconômico é perpassada no Brasil pelo fator étnico. Em virtude do passado escravocrata do país, boa parte da população das favelas e periferia é negra, descendente dos negros escravizados trazidos da África, que por não contarem com políticas sociais após a conquista da sua liberdade reproduziram o quadro geral de pobreza para os seus descendentes. Entretanto, existe também a auto segregação que é quando o indivíduo escolhe morar longe do centro e do restante da cidade, pois os vê como ameaçadores. Nas grandes cidades a auto segregação está diretamente ligada à busca de segurança por parte da elite. (ibid.)

\footnotetext{
${ }^{5}$ Espaços econômicos são os espaços onde se concentram o comércio e os serviços. Espaços residenciais são os utilizados para residência.
} 
No que se refere a questão do acesso à moradia adequada, a Fundação João Pinheiro (FJP, 2018) no relatório do déficit habitacional no Brasil do ano de 2015 expõe um déficit urbano de 5.572 .700 domicílios $^{6}$. Concomitante a isto a Pesquisa por Amostra de Domicílios (Pnad) de 2015, também presente neste relatório, aponta que o Brasil possui 7,906 milhões de imóveis vagos, e 80,3\% destes imóveis estão em áreas urbanas. Ao relacionarmos estes dois estudos nos deparamos com uma enorme contradição e com a confirmação de algo que Engels (2015) elucida o problema da habitação não é um problema de falta de construção de moradias, mas da lógica social, conforme o autor explana:

Ora, de onde vem a escassez de moradia? Como surgiu? Como bom burguês, o senhor Sax não pode saber que ela é um produto necessário da forma burguesa da sociedade, que sem escassez de moradia não há como subsistir uma sociedade na qual a grande massa trabalhadora depende exclusivamente do salário e, portanto, da soma de mantimentos necessária para garantir sua existência e reprodução; na qual melhoramentos contínuos da maquinaria etc. deixam massas de trabalhadores; na qual violentas oscilações industriais recorrentes condicionam a existência de um numeroso exército de reserva de trabalhadores desocupados, por um lado, e, por outro, jogam temporariamente na rua uma grande massa de trabalhadores; na qual grandes massas de trabalhadores são concentradas nas metrópoles, e isso mais rapidamente do que, nas condições vigentes, surgem moradias para eles; na qual, portanto, encontram-se locatários até para os chiqueiros mais infames; na qual, por fim, o dono da casa, na qualidade de capitalista, tem não só o direito, mas também de certo modo, em virtude da concorrência, o dever de obter por sua casa, sem nenhum escrúpulo, os alugueis mais alto possíveis. Numa sociedade desse tipo, a escassez de moradia não é um acaso; é uma instituição necessária que só pode ser eliminada, com repercussões sobre a saúde, etc., quando a ordem social da qual ela se origina for revolucionada desde a base. (ENGELS, 2015, p. 31)

Conforme enfatiza Harvey (2014) a cidade e a qualidade de vida no capitalismo se tornaram mercadorias para aqueles que podem pagar. À vista disso, o acesso à moradia ocorre mediante a compra ou aluguel de imóveis ou terre-

${ }^{6}$ Esse déficit habitacional é calculado como a soma de quatro componentes: 1) domićlios precários; 2) coabitação familiar; 3) ônus excessivo com aluguel urbano; e 4) adensamento excessivo de domicílios. O cálculo é realizado de forma que não haja contagem duplicada de moradias. 
nos, ainda que o direito à moradia esteja expresso no artigo $6^{\circ}$ da Constituição Federal de 1988 como um dos direitos sociais de toda a população. No seu artigo $5^{\circ}$ a Constituição estabelece que as propriedades devem cumprir a sua função social e indica um procedimento para desapropriação por necessidade ou utilidade pública, ou por interesse social, mediante uma indenização em dinheiro.

Contudo, apesar de a Constituição preconizar o direito à moradia, as políticas habitacionais não são levadas adiante devido ao processo de Reforma do Estado pós transição ao neoliberalismo. Esta doutrina econômica adotada pelo capitalismo contemporâneo, para se recuperar da onda recessiva iniciada na década de 1970, visa reverter a queda da taxa de lucro e romper com as restrições sociopolíticas que limitam o seu movimento. O neoliberalismo herda algumas características do liberalismo clássico no que remete ao direito à propriedade privada e respeito ao livre mercado, e dispõe de novas características como a expansão das políticas de privatização, demonização do Estado e mundialização do capital. Neste processo de demonização do Estado, ele é posto como incapaz de gerir os serviços públicos de modo que "Na verdade, ao proclamar a necessidade de um "Estado minimo", o que pretendem os monopólios e seus representantes nada mais é que um Estado mínimo para o trabalho e máximo para o capital." (NETTO; BRAZ, 2012, p. 239, grifo do autor)

A consolidação do neoliberalismo no Brasil aconteceu de forma tardia, apenas na década de 1990, devido à forte resistência do movimento operário, sindical, estudantil e popular na década de 1980. É sabido que, a partir de 1990 um amplo processo de "contra-reformas" se inicia, ou seja, um grande processo de retirada de direitos.

Este conjunto de reformas neoliberais, ordenadas pela reforma do papel do Estado, desenvolve as bases materiais e ideológicas para a intensificação da mundialização financeira e da mundialização de uma nova sociabilidade burguesa, configurando novas dinâmicas à luta de classes, tanto no que se refere às relações entre centro e periferia do sistema - aprofundando a hierarquização planetária -, quanto em relação às dinâmicas de cada formação econômico-social - ampliando o desemprego e aprofundando as desigualdades. (LIMA, 2005, p. 296) 
$\mathrm{O}$ advento do neoliberalismo no Brasil começa durante o governo Fernando Collor de Mello (1990-1992) e se consolida durante o governo de Fernando Henrique Cardoso (FHC-1995-2003), que em 1995 publica o Plano Diretor de Reforma do Aparelho do Estado, elaborado pelo extinto Ministério da Administração Federal e Reforma do Estado (MARE), com os objetivos globais de:

- Aumentar a governança do Estado, ou seja, sua capacidade administrativa de governar com efetividade e eficiência, voltando a ação dos serviços do Estado para o atendimento dos cidadãos.

- Limitar a ação do Estado àquelas funções que lhe são próprias, reservando, em princípio, os serviços não-exclusivos para a propriedade pública não-estatal, e a produção de bens e serviços para o mercado para a iniciativa privada.

- Transferir da União para os estados e municípios as ações de caráter local: só em casos de emergência cabe a ação direta da União.

- Transferir parcialmente da União para os estados as ações de caráter regional, de forma a permitir uma maior parceria entre os estados e a União. (BRASIL, 1995, p. 56 - 57)

A promulgação deste Plano, na análise de Lima (2005, p. 219) promoveu significativas mudanças na sociedade brasileira:

O Estado deixa de ser o responsável direto pelo desenvolvimento econômico e social, ela produção de bens e serviços, para exercer a função de regulador desse desenvolvimento, transferindo a responsabilidade pela sua execução para o setor privado, através da política de privatização, e para o setor público não-estatal, um setor subsidiado, parcialmente, pelo Estado que executaria serviços não exclusivos do Estado. A reforma do Estado é identificada, portanto, como estratégia fundamental para garantir a estabilidade econômica e o combate à inflação, iniciados com o lançamento do Plano Real e o adequado ajuste fiscal para sanear o Estado brasileiro.

Netto (1996) aponta que no Brasil após década de 1990 ocorrem transformações na sociedade, que afetam diretamente o conjunto da vida social. O autor, resumidamente pontua quatro elementos importantes que expressam suas ideias: 1-) as mudanças nas relações Estado/sociedade civil; 2-) A altera- 
ção nas formas de sociabilidade (sociabilidade do mercado); 3-) A alteração na forma de produção, organização e gestão do Trabalho (na esfera da produção, o padrão fordista-taylorista tende a se sobrepor); 4-) A lógica da financeirização. Para além destes elementos, neste contexto a disputa pelos fundos públicos intensifica-se. São realizados cortes nos gastos estatais com direitos e políticas sociais e uma mudança de pauta regressiva, sob os argumentos ideológicos de escassez de recursos, necessidade de conter o déficit público e equilibrar as contas públicas.

As políticas sociais, neste cenário são caracterizadas como paternalistas e geradoras de desequilíbrio, que devem ser acessadas via mercado. A consequência disto são as tendências de desresponsabilização e desfinancimento da proteção social pelo Estado. A orientação dos organismos internacionais para a política social é a focalização das ações, com estímulos a fundos sociais de emergência, programas de transferência de renda, bem como o fomento deste atendimento por organizações filantrópicas e não governamentais. A ideia de direito é substituída pela ideia de favor e de assistencialismo. (BEHRING, 2009)

Também aparece na Constituição Federal de 1988 e no Estatuto das Cidades, de 2001, a usucapião, que é o direito de aquisição de uma propriedade pela posse prolongada na mesma. Todavia, assim como o direito à moradia esta garantia legal de nada vale na ordem do capital pelo Estado desempenhar o papel de "comitê que administra os negócios comuns da classe burguesa como um todo" (MARX, 2008, p. 12) e não ter interesse em solucionar o problema da moradia,

Está claro como a luz do sol que o Estado atual não pode nem quer remediar o flagelo da falta de moradias. O Estado nada mais é que a totalidade do poder organizado das classes possuidoras, dos proprietários de terras e dos capitalistas em confronto com as classes espoliadas, os agricultores e os trabalhadores. O que não querem os capitalistas individuais tampouco quer o seu Estado. Portanto, embora individualmente o capitalista lamente a escassez de moradia, dificilmente mexerá um dedo para dissimular mesmo que superficialmente suas consequências mais terríveis, e o capitalista lobal, o Estado, também não fará mais do que isso. Quando muito, tomará providências para que o grau de dissimulação superficial que se tornou usual seja aplicado em toda parte do mesmo 
modo. Vimos que é exatamente isso que ocorre. (ENGELS, 2015, p. 99100)

O enfrentamento da questão da habitação quando não está pautado no uso da violência, por meio de remoções, é centrado na construção de novas habitações. Esta é a maneira com que o Estado, no que se refere as políticas de habitação, incorpora algumas das demandas da classe trabalhadora, ao mesmo tempo que preserva os interesses do capital e permite a sua reprodução. "A conciliação de interesses desiguais e contraditórios”, das diferentes classes, “[...] tanto propicia a continuidade e aceleração da produção de mais-valia como permite contornar o agravamento das contradições de classes além dos limites convenientes à vigência do regime” capitalista. (IANNI, 1988, p. 72). A opção por centrar a resposta ao problema da habitação pela construção de novas moradias é o Estado fazendo uso do consenso, o que não quer dizer que ele abandonará o uso da coerção - remoções -, quando for necessário, ele faz uso das duas alternativas para a preservação do status quo, conforme apontou Gramsci (2011).

Neste sentido, desde a década de 1960 foram lançados no Brasil três grandes programas em âmbito nacional que visavam, em especial, a aquisição da casa própria ou construção de novas moradias, os quais serão discutidos no item a seguir.

\section{A LÓGICA DA CIDADE MERCADORIA: DO BANCO NACIONAL DE HABITAÇÃO (BNH) AO PROGRAMA CASA VERDE E AMARE- LA (PCVA)}

Conforme aponta Rolnik (2019), embora já existisse um mercado para a venda de apartamentos desde o final dos anos 1920, no estado do Rio de Janeiro, e dos anos de 1940, em São Paulo foi somente após a Segunda Guerra Mundial (1939-1945) que surgiu um setor de incorporação imobiliária especializado e profissionalizado atuando como um verdadeiro mercado de residências próprias. A partir dos anos 1950, as incorporadoras poderiam ser empresas associadas a bancos, negócios familiares de construção ou companhias seguradoras e de capitalização. Contudo, apenas em 1964 que se constitui um banco pú- 
blico especializado em financiamento habitacional, o Banco Nacional da Habitação $(\mathrm{BNH})$, entre as reformas lançadas pelo governo após o golpe militar.

O lançamento do BNH se deu pela coalizão de interesses empresariais, particularmente ligados a construção civil. Antes do golpe militar Lacerda já havia anunciado o compromisso público de instituir um Banco Nacional de Habitação e promover a construção de milhares de casas populares, provendo o trabalhador a proprietário e dando “[...] às classes médias um lugar ao sol”. (MELLO, 1988, p. 76 apud ROLNIK, 2019, p. 282) O BNH foi se transformando em um dos elementos centrais da estratégia dos governos miliares por ter dinamizado a economia através da geração de empregos e fortalecimento da indústria da construção civil.

Ao ser convertido em empresa pública, no ano de 1966, o BNH se torna um instrumento privilegiado de financiamento interno da economia do país. Com a criação do Fundo de Garantia do Tempo de Serviço (FGTS), que se passou a ser o principal funding do $\mathrm{BNH}$, a dimensão financeira do programa foi fortalecida, ao subordinar as decisões sobre quem teria acesso, onde e de que forma iria se investir em habitação à necessidade de remuneração de recursos do fundo. Em parte, isto explica o porquê de entre os anos 1970 e 1986, apenas $30 \%$ dos 4,5 milhões de financiamentos habitacionais concedidos através do $\mathrm{BNH}$ foram destinados aos setores com menor renda e o início do financiamento de grandes obras de infraestrutura pelo banco. O BNH acabou por ser um programa de crédito habitacional para a compra da casa própria pela a classe média e após 22 anos de existência foi extinto, no ano de 1986, pelo contexto geral de crise do regime militar, e devido à crise na sua liquidez, recessão econômica e o aumento da inadimplência que lhe gerou um rombo, e pela ruptura entre os interesses empresariais e políticos que se articularam para a sua criação. (ROLNIK, 2019)

No ano de 2009, pela lei ${ }^{\circ} 11.977$, foi implementado o "Programa Minha Casa Minha Vida" (PMCMV), maior programa habitacional da história do Brasil até então, sob a justificativa de solução do problema habitacional. Entretanto, conforme a análise de Boulos (2014), este programa foi lançado para o aliviar o capital imobiliário de uma crise do ano de $2008^{7}$

\footnotetext{
${ }^{7}$ Essa crise no ano de 2008 estourou nos Estados Unidos da América justamente por causa do mercado imobiliário, nesta época, por conta da especulação imobiliária, muitas casas foram
} 
O programa foi desenvolvido com o objetivo central de salvar o capital imobiliário, injetando $\mathrm{R} \$ 34$ bilhões em recursos públicos para as empresas privadas. E neste ponto deu certo: as empresas do ramo puxaram a alta da Bolsa de Valores de São Paulo em 2009 e atraíram interesses no mundo todo. Hoje, $75 \%$ das ações das maiores construtoras do país estão nas mãos de investidores estrangeiros! (BOULOS, 2014, p. 21-22)

Outro fator que contradiz o argumento de que o maior objetivo do programa foi viabilizar o acesso à moradia pelas camadas populares é referente ao público atendido pelo PMCMV. O programa era dividido em faixas de acordo com a renda familiar, podendo atender famílias com uma renda familiar mensal de até $\mathbf{R} \$ 7.000,00$. Estas famílias da maior faixa de renda, da faixa 3, não contam com subsídios para adquirir imóveis, todavia, tem acesso a uma taxa de juros menor do que a do mercado.

Para a menor faixa de renda, constituída pelas famílias com renda familiar mensal de até $\mathrm{R} \$ 1.800,00$, as mais fragilizadas no que se refere a questão da moradia, o que se tinha era o reforço das desigualdades existentes, pois a responsabilidade pela construção das habitações era repassada para a iniciativa pri$\operatorname{vada}^{8}$. O resultado deste repasse são moradias de baixa qualidade, muito pequenas, longe dos centros urbanos e em lugares periféricos deficientes de serviços públicos, pois a construção destas habitações não era acompanhada de projetos de infraestrutura urbana.

Apesar da criação do PMCMV também ter sido importante pelo significativo número de vagas de empregos abertas na construção civil, este programa acabou por piorar a vida nas cidades. Pois os grandes investimentos na construção civil promoveram um boom imobiliário que aumentou o preço da terra, dos imóveis e dos alugueis, tendo como resultado a expulsão dos mais

vendidas a preço acima do mercado, a sua compra era realizada via empréstimos bancários (que tinham como garantia o próprio imóvel). Por um tempo este negócio foi muito lucrativo, entretanto, muitos dos compradores acabaram por não conseguir pagar as parcelas dos empréstimos, neste processo muitas pessoas foram despejadas, bancos declararam falência, e uma crise internacional no setor imobiliário foi desencadeada. A implantação do MCMC aqui no Brasil serviu para aliviar esta crise devido à aquisição de ações por investidores estrangeiros. (BOULOS, 2014)

${ }^{8} \mathrm{O}$ dinheiro é repassado e as empreiteiras são responsáveis por escolher a localização e as especificações dos empreendimentos. 
pobres para cada vez para mais longe das regiões centrais da cidade, lugar com mais concentração de empregos e serviços públicos.

As cidades explodiram horizontalmente, algo que todo urbanista condena, porque você tem de estender a rede de água, esgoto, de transporte. Quem paga por isso? Todos. E os que ganham são muito poucos: as empreiteiras, as incorporadoras imobiliárias e os donos de terrenos. (MARICATO, 20189)

Os despejos foram retomados de forma violenta, além disso favelas localizadas em regiões centrais e alvo de interesse do capital imobiliário se tornaram alvos de incêndios criminosos. Boulos (2015) as metrópoles brasileiras se tornaram, nos últimos anos, grandes produtoras de novos sem-teto.

O PMCMV, apesar de ser o primeiro programa habitacional com subsídios do governo federal, foi, na verdade, uma retomada da visão empresarial da política habitacional, por construir mais casas sem levar em consideração o espaço urbano como um todo e a cidade já comprometida com a baixa qualidade (MARICATO, 2015). Enquanto o foco da política de habitação permaneceu na construção de novas moradias, as favelas e periferias permaneceram descuidadas, Maricato $(2018)^{10}$ destaca que "[...] tem que fazer as duas coisas ao mesmo tempo. Construir sem regular as áreas já ocupadas gera uma demanda fora da cidade consolidada".

Ainda que reforçasse a lógica da cidade mercadoria, o PMCMV possuía uma modalidade voltada aos movimentos sociais, cooperativas, associações ou entidades da sociedade civil sem fins lucrativos, chamada "Entidades". Esta modalidade propiciou interessantes experiências pelo país devido a construção ou reforma das habitações ficar a cargo das entidades. No caso do Movimento dos Trabalhadores Sem Teto (MTST) esta modalidade possibilitou a construção de conjuntos habitacionais com apartamentos de metragem maior que os ofertados na faixa 1 do programa, e planejados de forma coletiva, como o condomínio João Cândido em São Paulo.

\footnotetext{
${ }^{9}$ Disponível em: < https://g1.globo.com/economia/noticia/minha-casa-minha-vida-pioroucidades-e-alimentou-especulacao-imobiliaria-diz-ex-secretaria-do-governo-lula.ghtml $>$.

Acesso em: 19 ago. 2020.

${ }^{10}$ idem
} 
No Rio de Janeiro, se tem a conquista pelo Movimento Nacional de Luta por Moradia (MNLM) da Ocupação Manuel Congo no centro da cidade, localizada em um antigo prédio público abandonado. Esta conquista, que completou 10 anos em 2018, só foi possível a partir de muita luta do movimento, antes de chegarem ao prédio atual as famílias haviam sido removidas de outros dois prédios na cidade. Posteriormente a aquisição do edifício pelo Fundo Nacional de Habitação de Interesse Social (FNHIS), o prédio foi reformado com verbas do PMCMV Entidades. Conforme avalia a coordenadora do movimento, a escolha do prédio não foi aleatória, o movimento acredita que morar no Centro é bom para eles por terem fácil acesso a trabalho, escolas, creches, postos de saúde e comércio, mas também para os cofres públicos por economizarem com grandes investimentos em infraestrutura. O movimento acredita na "[...] ocupação do centro como uma política urbana que deve ser empregada na Região Metropolitana” (CAU/RJ, 2018) ${ }^{11}$.

Esta modalidade do PMCMV foi a primeira a ser extinta, ainda em 2016, após Michel Temer (2016-2018) assumir a presidência. Os acordos já conquistados pelos movimentos sociais e outras entidades foram cancelados e não retomados apesar de toda a pressão realizada pelos movimentos sociais. Porém, ainda houve a entrega de obras que estavam quase finalizadas.

Embora o cenário que já não fosse muito positivo para as políticas habitacionais, tem-se experimentado maiores retrocessos com o avanço do conservadorismo reacionário atrelado a ofensiva neoliberal ${ }^{12}$. O novo governo que assumiu a presidência, no ano de 2019, extinguiu o Ministério das Cidades, esvaziou o PMCMV no decorrer do ano e em dezembro de 2019 anunciou oficialmente o fim de investimentos na faixa 1 do programa.

No final de agosto de 2020 foi enviada para o Congresso Nacional a Medida Provisória (MP) n ${ }^{\circ}$ 996, de 2020, que institui o Programa Casa Verde e Amarela (PCVA), em 12 de janeiro de 2021, após ter sofrido algumas pequenas alterações, foi promulgado pela lei $n^{\circ} 14.118$. A sua finalidade expressa na lei é:

\footnotetext{
${ }^{11}$ Disponível em: < https://www.caubr.gov.br/ocupacao-manuel-congo-no-centro-do-rio-emodelo-para-habitacao-popular/ > . Acesso em: 20 set. 2020.

12 É importante ressaltar que este movimento não é restrito ao Brasil, faz parte do movimento do capital em escala mundial.
} 
[...] promover o direito à moradia a famílias residentes em áreas urbanas com renda mensal de até $\mathrm{R} \$ 7.000,00$ (sete mil reais) e a famílias residentes em áreas rurais com renda anual de até $\mathrm{R} \$ 84.000,00$ (oitenta e quatro mil reais), associado ao desenvolvimento econômico, à geração de trabalho e de renda e à elevação dos padrões de habitabilidade e de qualidade de vida da população urbana e rural. (BRASIL, 2021)

Além do financiamento imobiliário, este programa prevê regularização fundiária e melhoria de habitações. Conforme o artigo 25 da lei de sua promulgação, desde o dia 26 de agosto de 2020 todas as operações com benefício habitacional, geridas pelo governo federal, integram o PCVA. Ou seja, o programa mais rebatiza e remodela políticas habitacionais já existentes do que institui algo novo, pois as operações habitacionais continuam a submeter-se às regras da Lei $\mathrm{n}^{\mathrm{o}} 11.977$ de 7 de julho de 2009, que instituiu a regularização fundiária e o PMCMV.

Dando continuidade a facilitação da venda de imóveis da União a entes privados, a partir da lei do PCVA foi dispensada a necessidade de autorização legislativa específica para isto, desde que parte do imóvel seja destinado a políticas públicas habitacionais, esta destinação ocorrerá por meio de licitação. Cumpridas as contrapartidas expressas no contrato, o ente privado terá liberdade para explorar economicamente a parte do imóvel não afetada por elas.

O PCVA conta com três faixas de renda, a faixa 1 contempla as famílias com renda bruta de até $\mathrm{R} \$ 2$ mil mensais; a faixa 2 famílias com renda entre $\mathrm{R} \$ 2$ e R $\$ 4$ mil; e a faixa 3, famílias com renda entre $\mathrm{R} \$ 4$ mil e $\mathrm{R} \$ 7$ mil. Para a aquisição de moradia, a faixa 1 terá acesso a uma taxa de juros que pode chegar até $4,75 \%$ ao ano e subsídio de até $\mathrm{R} \$ 47.500,00$, de acordo com a renda e região onde mora; os subsídios para a faixa 2 podem chegar até $\mathrm{R} \$ 29.000,00$, a depender da sua renda mensal e da localização do imóvel; para a faixa 3 são oferecidas atrativas taxas de juros. (CAIXA, 2020). Para a faixa 1 também estarão disponíveis as modalidades de regularização fundiária e melhoria habitacional, e, para as famílias das faixas 2 e 3 com renda de até $\mathrm{R} \$ 5.000,00$ a regularização fundiária.

No que se refere ao crédito imobiliário, apesar de anunciar a menor taxa de juros da história, e oferecer taxas de juros menores para as Regiões Norte e Nordeste do país, por não oferecer um subsídio forte relembra o pro- 
grama de financiamento do $\mathrm{BNH}$, que estava condicionado a concessão de crédito, se configurando como um programa de financiamento para a classe média, por excluir a camada mais pobre da população que não atende aos critérios para fornecimento de crédito, mas que concentra a maior necessidade habitacional.

Contudo, apesar de aparentar à primeira vista apenas um retrocesso ao antigo modelo de financiamento empregado durante a ditadura empresarial militar, é imprescindível se atentar para as mudanças. Guerreiro (2020) aponta que em vez de ser um mero retrocesso, o PCVA parece ser na verdade um avanço do setor imobiliário brasileiro em direção as formas mais atuais de acumulação de capital, mais ligadas ao mercado financeiro. Os moldes deste programa abrem mais possibilidades de investimento de capital, pois transforma "[...] o que é bem fixo (casas), em ativos mobiliários, títulos negociáveis no mercado financeiro"(ibid) $)^{13}$.

É necessário compreender o PCVA dentro do contexto do atual modelo de acumulação, com a hegemonia da indústria financeira e por ele abrir mais uma possibilidade de investimento de capital. Além de uma alternativa adotada pelo governo federal para a recuperação da economia brasileira, considerando que o setor da construção civil não teve estagnação com a pandemia da Covid19.

\section{4- CONSIDERAÇÕES FINAIS}

Conforme dito no início do texto, as cidades são anteriores ao capitalismo, contudo, foi a partir dele que elas adquiriram o caráter de mercadoria, Maricato (2015) afirma que o capitalismo mudou as cidades a tal ponto que hoje é impossível o pensar dissociado delas. O capitalismo vai moldando as cidades em cada período histórico de acordo com os seus interesses.

No que diz respeito à habitação da classe trabalhadora, esta nunca foi centro de interesse do capital, por isso que, de um modo geral, os bairros de moradia da classe trabalhadora foram produzidos por ela mesma por meio da

\footnotetext{
13 Disponível em: < http://www.labcidade.fau.usp.br/casa-verde-e-amarela-securitizacao-esaidas-da-crise-no-milagre-da-multiplicacao-O-direito-ao-endividamento/ >. Acesso em: 19 set. 2020.
} 
autoconstrução de moradias, no seu tempo de descanso, e as favelas ou moradias ilegais se constituem como parte estrutural das cidades de países periféricos como o Brasil, não exceções (ibidem). Quando esta área desperta o interesse do capital ocorre a remoção das camadas populares que nela habitam, esta é uma das condições para a evolução da cidade capitalista.

Assim, o Brasil experimentou períodos de investimento em políticas sociais e algumas no que tangem a política habitacional, contudo, mesmo os períodos de investimentos na área da habitação não foram suficientes para solucionar o problema do déficit de moradia, pois como Engels (2015) destacou o problema da habitação não é um problema de construção de casa, mas da lógica social. Embora tenhamos vivido períodos de investimentos inéditos na construção de moradias, a escassez aumentou nas grandes metrópoles devido aos novos sem-teto criados pela especulação imobiliária que promoveu um boom no valor dos alugueis e pela reformulação urbana. (BOULOS, 2015).

O PCVA começou a valer a partir da data da publicação da MP, contudo, sofreu algumas alterações até a promulgação da sua lei. Por ter sido instituído pouco tempo antes da elaboração deste artigo não se pôde trazer maiores considerações sobre ele. Entretanto, já é possível presumir os desafios que os movimentos sociais e a luta por moradia no Brasil enfrentarão, devido à falta de uma modalidade que os contemple. Ao não integrar os movimentos sociais e entidades organizadas da sociedade civil e não oferecer um forte subsídio, como os até $90 \%$ ofertados pelo PMCMV para a menor faixa de renda, o programa deixa de fora quem mais precisa ter acesso à moradia adequada.

O MTST (2020) após o lançamento do PCVA lançou uma nota oficial onde critica a MP de criação do programa e afirma que vai continuar lutando por uma habitacional que de fato garanta o direito à moradia aos que mais necessitam.

\section{REFERÊNCIAS}

BRASIL. Constituição (1988). Constituição da República Federativa do Brasil. Brasília, DF: Senado, 1988. 
. Presidência da República. Lei no 14.118, de 12 de janeiro de 2021. Institui o Programa Casa Verde e Amarela

. Presidência da República. Medida Provisória n 996, de 25 de agosto de 2020. Institui o Programa Casa Verde e Amarela.

- Presidência da República. Plano Diretor da Reforma do Aparelho do Estado. Brasília: Presidência da República, Câmara da Reforma do Estado, Ministério da Administração Federal e Reforma do Estado, 1995. Disponível em:

<http://www.biblioteca.presidencia.gov.br/publicacoes-oficiais/catalogo/ fhc/plano-diretor-da-reforma-do-aparelho-do-estado-1995.pdf $>$. Acesso em: 12 set. 2020 .

. Vice-presidente da república no cargo de Presidente da República. Lei $\mathbf{n}^{\mathbf{0}} \mathbf{1 1 . 9 7 7}$ de 7 de julho de 2009. Dispõe sobre o Programa Minha Casa, Minha Vida - PMCMV e a regularização fundiária de assentamentos localizados em áreas urbanas.

BEHRING, E. R. As novas configurações do Estado e da Sociedade Civil no contexto da crise do capital. In: CFESS; ABEPSS (org.). Serviço Social: direitos sociais e competências profissionais. Brasília: CFESS; ABEPSS, 2009, p. $69-86$.

BOULOS, G. Por que ocupamos? Uma introdução à luta dos Sem Teto. 2. ed. São Paulo: Scortecci, 2014.

. De que lado você está? Reflexos sobre a conjuntura política e urbana no Brasil. 1. ed. São Paulo: Boitempo, 2015.

CAIXA. Casa Verde e Amarela - Habitação Urbana - Recursos FGTS. Caixa, 27 de nov de 2020. Disponível em: < $\underline{\text { https://www.caixa.gov.br/voce/habita- }}$ cao/casa-verde-e-amarela/urbana/Paginas/default.aspx $>$. Acesso em: 10 jan 2020. 
CAU/RJ. Ocupação Manuel Congo, no Centro do Rio, é modelo para habitação popular. In: CAU/BR. Conselho de Arquitetura e Urbanismo do Brasil, 07 de maio de 2018. Disponível em: < https://www.caubr.gov.br/ocupacao-manuel-congo-no-centro-do-rio-e-modelo-para-habitacao-popular/ > . Acesso em: 20 set. 2020 .

ENGELS, F. A situação da classe trabalhadora na Inglaterra. São Paulo: Boitempo, 2008.

. Sobre a questão da moradia. 1. ed. São Paulo: Boitempo, 2015.

FARAGE, E. Experiências Profissionais do Serviço Social nos Movimentos Sociais Urbanos. In: ABRAMIDES, M. B.; DURIGUETTO, M. L. (orgs.) Movimentos Sociais e Serviço Social - uma relação necessária. São Paulo: Cortez, 2014, p. $245-262$.

FERNANDES, Florestan. Sociedade de classes e subdesenvolvimento. 5. ed. rev. - São Paulo: Global, 2008.

FUNDAÇÃO JOÃO PINHEIRO. Déficit habitacional no Brasil 2015. Diretoria de Estatística e Informações. Belo Horizonte: FJP, 2018.

GRAMSCI, A. O Leitor de Gramsci: escritos escolhidos 1916-1935. Rio de Janeiro: Civilização Brasileira, 2011.

GUERREIRO, I. A. Casa Verde e Amarela, securitização e saídas da crise: no milagre da multiplicação, o direito ao endividamento. LabCidade, São Paulo, 02 set. 2020. Disponível em: < $\underline{\text { http://www.labcidade.fau.usp.br/casa-verde-e- }}$ amarela-securitizacao-e-saidas-da-crise-no-milagre-da-multiplicacao-O-direito-ao-endividamento/>. Acesso em: 19 set. 2020.

HARVEY, D. Cidades Rebeldes: do direito à cidade à revolução urbana. São Paulo: Boitempo, 2014.

IANNI, O. Dialética \& Capitalismo: ensaio sobre o pensamento de Marx. Petrópolis: Vozes, 1988.

LEFEBVRE, H. O Direito à Cidade. Trad. Rubens Eduardo Frias. 5. ed. São Paulo: Editora Centauro, 2001. 
LIMA, K. Reforma da Educação Superior nos anos de contra-revolução neoliberal: de Fernando Henrique Cardoso a Luis Inácio Lula da Silva. 2005. 466 f. Tese (Doutorado em Educação) - Faculdade de Educação, Universidade Federal Fluminense, Rio de Janeiro, 2005.

MARICATO, E. Para entender a crise urbana. 1. ed. São Paulo: Expressão Popular, 2015.

. Minha Casa Minha Vida piorou cidades e alimentou especulação imobiliária, diz ex-secretária do governo Lula. BBC, 04 jun. 2018. Disponível em:

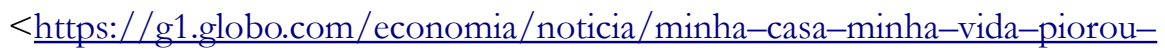
cidades-e-alimentou-especulacao-imobiliaria-diz-ex-secretaria-do-governolula.ghtml >. Acesso em: 19 ago. 2020.

MARX, K. Manifesto do partido comunista. 1. ed. São Paulo: Expressão Popular, 2008.

MTST. Nota Oficial - Programa Casa Verde e Amarela. MTST, 27 ago. 2020. Disponível em: < https://mtst.org/mtst/nota-oficial-programa-casa-verde-eamarela/>. Acesso em: 20 set. 2020.

NET'TO, J. P. Transformações societárias e Serviço Social. Revista Serviço Social e Sociedade, São Paulo, n. 50, ANO XVII, abril de 1996, p. 87 - 129.

.; BRAZ, M. Economia política: uma introdução crítica. 8. ed. São Paulo: Cortez, 2012.

NOVACK, G. O desenvolvimento desigual e combinado na história. São Paulo: Editora Instituto José Luís e Rosa Sundermann, 2008.

ROLNIK, R. Guerra dos Lugares: a colonização da terra e da moradia na era das finanças. 2. ed. São Paulo: Boitempo, 2019.

SANCHEZ, F. A Reinvenção Das Cidades Na Virada De Século: agentes, estratégias e escalas de ação política. Revista de Sociologia e Política, Curitiba, n. 16, p. 31-49, jun. 2001.

SOUZA, M. L. de. ABC do Desenvolvimento Urbano. Rio de Janeiro: Editora Bertrand, 2005. 
TOPALOV, C. Da questão social aos problemas urbanos: os reformadores e a população das metrópoles em princípios do século XX. In: RIBEIRO, L. C.; PECHMAN, R. Cidade, povo e nação. Rio de Janeiro: Civilização Brasileira, 1996 , p. $23-51$.

VALLADARES, L. A Gênese da Favela Carioca: a produção anterior às ciências sociais. Revista Brasileira de Ciências Sociais, São Paulo, v. 15, n. 55, out. 2000 , p. $5-34$. 